\title{
Randomized comparative study of left versus right radial approach in the setting of primary percutaneous coronary intervention for ST-elevation myocardial infarction
}

\author{
This article was published in the following Dove Press journal: \\ Clinical Interventions in Aging \\ 24 June 2015 \\ Number of times this article has been viewed
}

\section{Qiang Fu \\ Hongyu $\mathrm{Hu}$ \\ Dezhao Wang \\ Wei Chen \\ Zhixu Tan \\ Qun Li \\ Buxing Chen}

Department of Cardiology, Beijing Titantan Hospital, Capital Medical University, Beijing, People's Republic of China
Correspondence: Buxing Chen Department of Cardiology, Beijing Titantan Hospital, Capital Medical University, No 6 Tiantanxili, Dongcheng District, Beijing 100050, People's Republic of China

Tel +86 I0 67096572

Fax +861067096572

Email chbux@I26.com
Background: Growing evidence suggests that the left radial approach (LRA) is related to decreased coronary procedure duration and fewer cerebrovascular complications as compared to the right radial approach (RRA) in elective percutaneous coronary intervention (PCI). However, the feasibility of LRA in primary PCI has yet to be studied further. Therefore, the aim of this study was to investigate the efficacy of LRA compared with RRA for primary PCI in ST-elevation myocardial infarction (STEMI) patients.

Materials and methods: A total of 200 consecutive patients with STEMI who received primary PCI were randomized to LRA (number $[n]=100)$ or RRA $(n=100)$. The study endpoint was needle-to-balloon time, defined as the time from local anesthesia infiltration to the first balloon inflation. Radiation dose by measuring cumulative air kerma (CAK) and CAK dose area product, as well as fluoroscopy time and contrast volume were also investigated.

Results: There were no significant differences in the baseline characteristics between the two groups. The coronary procedural success rate was similar between both radial approaches $(98 \%$ for left versus $94 \%$ for right; $P=0.28$ ). Compared with RRA, LRA had significantly shorter needle-to-balloon time (16.0 \pm 4.8 minutes versus $18.0 \pm 6.5$ minutes, respectively; $P=0.02$ ). Additionally, fluoroscopy time ( $7.4 \pm 3.4$ minutes versus $8.8 \pm 3.5$ minutes, respectively; $P=0.01$ ) and CAK dose area product (51.9 $\pm 30.4 \mathrm{~Gy} \mathrm{~cm}^{2}$ versus $65.3 \pm 49.1 \mathrm{~Gy} \mathrm{~cm}^{2}$, respectively; $P=0.04$ ) were significantly lower with LRA than with RRA.

Conclusion: Primary PCI can be performed via LRA with earlier blood flow restoration in the infarct-related artery and lower radiation exposure when compared with RRA; therefore, the LRA may become a feasible and attractive alternative to perform primary PCI for STEMI patients.

Keywords: transradial approach, primary percutaneous coronary intervention, ST-segment elevation myocardial infarction

\section{Introduction}

Previous studies have shown that the transradial cardiac catheterization has decreased not only bleeding complications related to the access site, but also morbidity and hospitalization as compared to the transfemoral approach. ${ }^{1-5}$ Even in patients with ST-elevation myocardial infarction (STEMI), the radial approach was linked to a significant reduction in major adverse cardiac events. ${ }^{6}$ At present, the right radial approach (RRA) has become the first choice routinely for coronary angiography and interventions in daily clinical practice due to the operator's comfort. However, several observations have revealed that the left radial approach (LRA) is thought 
to be easier for catheter manipulation, and it may reduce procedure time and cerebrovascular complications when compared with RRA. ${ }^{7-9}$ Likewise, our previous study also showed similar results. ${ }^{10}$ In general, STEMI patients were excluded from such investigations. Although the survival of STEMI patients is closely associated with reperfusion time, no prospective randomized studies have evaluated the effect of the transradial approach (left versus right) on reperfusion time for STEMI patients undergoing primary percutaneous coronary intervention (PCI). Until now, it remains unclear whether primary PCI via LRA or RRA differs in real-world practice. Therefore, we carried out a prospective, randomized study to investigate the difference between the LRA and RRA in the setting of primary PCI for STEMI.

\section{Materials and methods}

\section{Study population}

All patients with STEMI were screened for eligibility from November 2012 to December 2014. Patients could be included within 12 hours of symptom onset for primary PCI. The exclusion criteria included cardiogenic shock and previous coronary artery bypass graft surgery. The included patients were randomized to either the LRA or RRA using a computerized 1:1 randomization sequence. A specially assigned staff member who did not perform the coronary interventions managed the randomization list and informed the operator of the radial approach used at the beginning of the coronary procedure; thus, the operator did not know which radial approach should be used before the coronary procedure. Transradial primary PCI was performed by three experienced operators who independently completed more than 300 transradial PCI procedures before the study.

The study was designed and carried out in accordance with the principles of the Declaration of Helsinki, and it was approved by the ethics committee of Beijing Titantan Hospital (Beijing, People's Republic of China). All patients provided written informed consent. This study protocol was registered at ClinicalTrials.gov (NLM identifier: NCT02239757).

\section{Transradial cardiac catheterization}

Regardless of the LRA or RRA, all coronary procedures were performed on the right side of the patient. Before the coronary procedure, all patients were administered with $300 \mathrm{mg}$ of aspirin and a loading dose of clopidogrel (600 mg). After local anesthesia by 1\% lidocaine, access was obtained using the Seldinger technique with a 20 -gauge needle, and a 6 French radial sheath was inserted. Because low-molecular-weight heparins are associated with a reduction in mortality and major bleeding rates in STEMI patients treated with primary PCI as compared to unfractionated heparin, ${ }^{11}$ enoxaparin $0.6-0.8 \mathrm{~mL}$, according to the weight of the patients, was administered after sheath insertion in this study. Antispasm medications were not routinely used, and in the case of a radial spasm, nitroglycerine 100-200 $\mu \mathrm{g}$ was administered.

Primary PCI was performed with standard 6 French guiding catheters after the coronary diagnostic procedure. The choices of guiding catheters and guide wires and the use of glycoprotein IIb/IIIa platelet receptor antagonists were left to the operator's discretion. Manual thrombus aspiration with a thrombus extraction catheter (Thrombuster II) was also performed at the discretion of the operators. After the end of the primary PCI, cumulative air kerma (CAK), CAK dose area product (CAK DAP), fluoroscopy time, and contrast volume were measured. The arterial sheath was removed immediately after the completion of the interventions, and a compression device (TR Band; Terumo Medical Corporation, Somerset, NJ, USA) was applied for hemostasis.

\section{Definitions and endpoints}

Procedure failure was considered as the impossibility to completely carry out the PCI using the access point of choice and the need to shift to the opposite approach. Needle-toballoon time was generally defined as the time from local anesthesia infiltration to the first balloon inflation. If a manual thrombectomy was conducted before balloon inflation, the needle-to-balloon time was also considered as the time from local anesthesia infiltration to the beginning of thrombus aspiration. The diagnosis of reinfarction required new pathological $\mathrm{Q}$ waves or the reelevation of creatine kinase $\mathrm{MB}>50 \%$ above the previous level if already above normal, or $\geq 3 \times$ the upper limit of normal following PCI, or $\geq 5 \times$ the upper limit of normal after bypass surgery.

The primary endpoint of the study was needle-to-balloon time. Secondary endpoints included radiation dose by measuring CAK and CAK DAP, fluoroscopy time, and contrast volume. Other clinical endpoints including vascular complications, death, reinfarction, urgent revascularization, stroke, and new congestive heart failure were evaluated during the hospitalization and at 30 days.

\section{Statistical analysis}

The sample size was estimated based on our early experience and data. To detect a difference of 2.0 \pm 4.8 minutes in reperfusion time with a power of 0.8 and an $\alpha$ error of 0.05 , 
the number of patients required was calculated to be at least 184 patients in all (92 patients in each group). Continuous variables are expressed as the mean \pm standard deviation, and categorical variables are expressed as frequencies and percentages. Differences between the two groups were determined using Student $t$-test for continuous variables. The $\chi^{2}$ test or Fisher's exact test was used as appropriate to compare categorical variables. Differences were considered significant at $P<0.05$. All statistical analyses were performed with SPSS 20.0 software (IBM Corporation, Armonk, NY, USA).

\section{Results}

A total of 200 patients undergoing primary PCI were randomized to either the RRA group (number $[n]=100$ ) or the LRA group $(n=100)$. The baseline characteristics of the population are summarized in Table 1. There were no significant differences in patient demographics and risk factors.

The rate of procedural success, considered as the possibility to completely carry out PCI via the radial access point of choice, was similar between both radial approaches (98 of 100 [98\%] patients for left versus 94 of 100 [94\%] patients for right; $P=0.28$ ). Six patients in the RRA group and two patients in the LRA group required crossover to

Table I Baseline characteristics of the study population

\begin{tabular}{|c|c|c|c|}
\hline Variable & $\begin{array}{l}\text { Right radial } \\
\text { approach } \\
(n=\mid 00)\end{array}$ & $\begin{array}{l}\text { Left radial } \\
\text { approach } \\
(n=100)\end{array}$ & $P$-value \\
\hline Age (years) & $59.6 \pm 12.3$ & $60.9 \pm 10.9$ & 0.41 \\
\hline Male & 79 (79\%) & 82 (82\%) & 0.59 \\
\hline Height (cm) & $167.9 \pm 6.2$ & $167.9 \pm 7.4$ & 0.98 \\
\hline Weight (kg) & $72.8 \pm 10.8$ & $71.1 \pm 10.9$ & 0.28 \\
\hline BMI $\left(\mathrm{kg} / \mathrm{m}^{2}\right)$ & $25.9 \pm 3.1$ & $25.4 \pm 2.8$ & 0.22 \\
\hline Creatinine $(\mu \mathrm{mmol} / \mathrm{L})$ & $71.8 \pm 19.9$ & $67.6 \pm 14.8$ & 0.10 \\
\hline Peak CK-MB (IU/L) & $225.4 \pm 189.6$ & $179.5 \pm 170.3$ & 0.07 \\
\hline Peak cTnl (ng/mL) & $16.9 \pm 12.6$ & $|4.7 \pm 1| .8$ & 0.19 \\
\hline LVEF (\%) & $56.9 \pm 10.3$ & $57.3 \pm 8.7$ & 0.76 \\
\hline Hypertension & $64(64 \%)$ & $55(55 \%)$ & 0.20 \\
\hline Diabetes mellitus & $22(22 \%)$ & $31(31 \%)$ & 0.15 \\
\hline Dyslipidemia & $16(16 \%)$ & $10(10 \%)$ & 0.21 \\
\hline Current smoking & $60(60 \%)$ & $56(56 \%)$ & 0.57 \\
\hline Anterior MI & 52 (52\%) & $54(54 \%)$ & 0.78 \\
\hline Inferior MI & $48(48 \%)$ & $46(46 \%)$ & 0.78 \\
\hline Killip class & & & 0.29 \\
\hline Killip I & $72(72 \%)$ & $69(69 \%)$ & \\
\hline Killip 2 & $26(26 \%)$ & $31(31 \%)$ & \\
\hline Killip 3 & $2(2 \%)$ & $0(0 \%)$ & \\
\hline Killip $4 *$ & $0(0 \%)$ & $0(0 \%)$ & \\
\hline
\end{tabular}

Notes: Data are expressed as the mean \pm SD or number (\%). *Excluded by study design.

Abbreviations: $n$, number; BMI, body mass index; $C K-M B$, creatinine kinase $M B$ isoenzyme; cTnl, cardiac troponin I; LVEF, left ventricular ejection fraction; MI, myocardial infarction; SD, standard deviation. the contralateral approach due to an inability to cannulate the radial artery. Finally, 192 patients (98 in the LRA group and 94 in the RRA group) were included and investigated in the present study (Figure 1 for a flow diagram of this study).

The angiographic and interventional data are shown in Table 2. Stents were used in all cases except for four in the RRA group and one in the LRA group. There were no differences in the number of stents used between both approaches, with an average of one stent per case. Intracoronary tirofiban was administered during the primary PCI procedure in more than $70 \%$ of the cases. Thrombus aspiration was applied in $23 \%$ of the LRA and $28 \%$ of the RRA cases $(P=0.41)$. Final thrombolysis in myocardial infarction (TIMI) 3 flow was achieved in more than $96 \%$ of the patients ( $96 \%$ for RRA versus $97 \%$ for LRA; $P=0.72$ ). No significant difference was observed in the contrast volume between both approaches (128.8 $\pm 17.2 \mathrm{~mL}$ for the RRA versus $125.8 \pm 19.6 \mathrm{~mL}$ for the LRA; $P=0.31$ ).

The details of the procedural durations and radiation exposure are depicted in Table 3. The LRA was associated with a significantly shorter needle-to-balloon time (16.0 \pm 4.8 minutes versus $18.0 \pm 6.5$ minutes; $P=0.02)$ and fluoroscopy time (7.4 \pm 3.4 minutes versus $8.8 \pm 3.5$ minutes; $P=0.01)$ when compared with the RRA, respectively. As for the radiation dose, although CAK was similar between both radial approaches, CAK DAP was significantly lower with the LRA than with the RRA $\left(51.9 \pm 30.4 \mathrm{~Gy} \mathrm{~cm}^{2}\right.$ versus 65.3 $\left.\pm 49.1 \mathrm{~Gy} \mathrm{~cm}^{2} ; P=0.04\right)$.

Thirty days' follow-up was complete in all patients. One patient suffered from severe congestive heart failure in the RRA group, whereas one patient died in the LRA group due to cardiac rupture and tamponade. No patients experienced reinfarction and stroke, and no patients required re-PCI or bypass surgery.

\section{Discussion}

The major finding of this study is that earlier blood flow restoration in infarct-related artery and lower radiation exposure can be achieved through the LRA in STEMI patients undergoing primary PCI when compared to those undergoing the RRA.

Transradial primary PCI has been proven as a valid alternative to the transfemoral approach, with fewer bleeding complications and major adverse events in the STEMI setting. ${ }^{12-16}$ Moreover, it is also feasible and safe to perform complex coronary interventions, such as chronic total occlusions, via the bilateral radial approach for experienced 


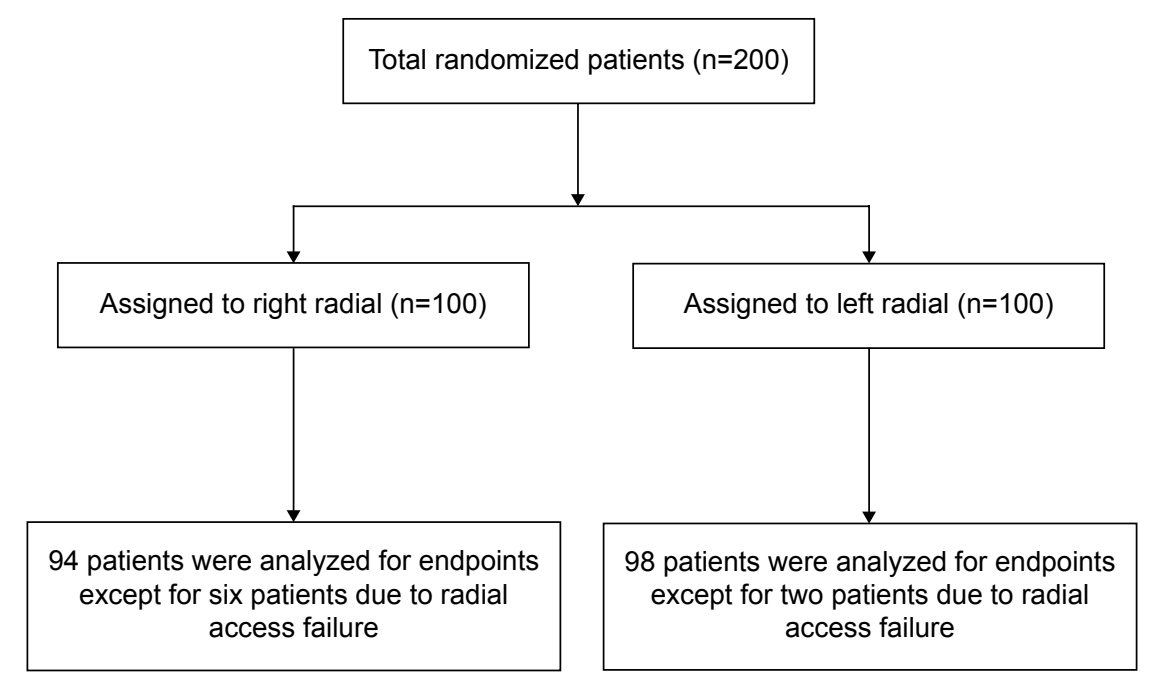

Figure I Flow diagram of the study.

Notes: Comparison between the left and right radial approach for primary coronary intervention in patients with ST-elevation myocardial infarction. Abbreviation: $\mathrm{n}$, number.

transradial PCI operators. ${ }^{17,18}$ Recently, several studies have shown that the LRA might be associated with shorter procedural time and lower cerebrovascular complications when compared with the RRA in elective PCI. ${ }^{7-9,19}$ Since mortality is increased with a time delay to reperfusion in STEMI patients, ${ }^{20,21}$ it is essential to shorten the reperfusion time when undergoing primary PCI. Thus, the choice of transradial access site could be an important consideration for primary PCI in patients with STEMI. However, it remains undetermined whether the LRA provides a shorter procedural time in STEMI patients undergoing primary PCI (similar to

Table 2 Angiographic and interventional characteristics of the study population

\begin{tabular}{|c|c|c|c|}
\hline Variable & $\begin{array}{l}\text { Right radial } \\
\text { approach } \\
(n=94)\end{array}$ & $\begin{array}{l}\text { Left radial } \\
\text { approach } \\
(\mathrm{n}=98)\end{array}$ & $P$-value \\
\hline Procedural success rate & $94 / 100$ (94\%) & $98 / 100(98 \%)$ & 0.28 \\
\hline Infarct-related artery & & & 0.84 \\
\hline Left anterior descending & $51(54 \%)$ & $54(55 \%)$ & \\
\hline Left circumflex & $10(11 \%)$ & $8(8 \%)$ & \\
\hline Right coronary artery & $33(35 \%)$ & $36(37 \%)$ & \\
\hline Initial TIMI flow $(0-1 / 2 / 3)$ & $78 / 12 / 4$ & $78 / 11 / 9$ & 0.39 \\
\hline Guiding catheter & & & 0.42 \\
\hline Judkins & $82(87 \%)$ & 91 (93\%) & \\
\hline Amplatz & $4(4 \%)$ & $2(2 \%)$ & \\
\hline Extra backup & $8(9 \%)$ & $5(5 \%)$ & \\
\hline Thrombus aspiration & $26(28 \%)$ & $22(23 \%)$ & 0.41 \\
\hline GP Ilb/llla inhibitors & 73 (78\%) & 76 (78\%) & 0.99 \\
\hline Final TIMI 3 flow & $90(96 \%)$ & 95 (97\%) & 0.72 \\
\hline Contrast volume $(\mathrm{mL})$ & $128.8 \pm \mid 7.2$ & $125.8 \pm 19.6$ & 0.31 \\
\hline Number of stents & $\mathrm{I} . \mathrm{I} \pm 0.4$ & $1.2 \pm 0.4$ & 0.22 \\
\hline
\end{tabular}

Note: Data are expressed as the mean \pm SD or number (\%).

Abbreviations: $\mathrm{n}$, number; TIMI, thrombolysis in myocardial infarction; GP, glycoprotein; SD, standard deviation. what is observed in the setting of elective PCI). To date, only a small retrospective study compared the LRA and RRA in STEMI patients undergoing primary PCI, and it showed no differences in the room-to-arterial cannulation time, roomto-balloon time, and total procedural time between both radial approaches. ${ }^{22}$

This is, to our knowledge, is the first prospective randomized investigation providing insight into how different transradial primary PCIs compare in patients with STEMI, especially with respect to the effect of the left or right transradial approach on procedural time. In the present study, we observed a significant reduction in the needle-to-balloon time, with an average of 2 minutes via the LRA compared to the RRA. According to our results, the LRA may contribute to reduce blood flow restoration time in infarct-related arteries for STEMI patients. Furthermore, the LRA is associated with shorter fluoroscopy time and reduced radiation dose when compared with the RRA. These results indicate that

Table 3 Procedural durations and radiation exposure of the study population

\begin{tabular}{llll}
\hline Variable & $\begin{array}{l}\text { Right radial } \\
\text { approach } \\
(\mathbf{n = 9 4 )}\end{array}$ & $\begin{array}{l}\text { Left radial } \\
\text { approach } \\
(\mathbf{n = 9 8 )}\end{array}$ & P-value \\
\hline $\begin{array}{l}\text { Needle-to-balloon time } \\
\text { (minutes) }\end{array}$ & $18.0 \pm 6.5$ & $16.0 \pm 4.8$ & 0.02 \\
Total CAK (mGy) & $720 \pm 359$ & $715 \pm 478$ & 0.92 \\
Total CAK DAP (Gy cm $\left.{ }^{2}\right)$ & $65.3 \pm 49.1$ & $51.9 \pm 30.4$ & 0.04 \\
Fluoroscopy time (minutes) & $8.8 \pm 3.5$ & $7.4 \pm 3.4$ & 0.01 \\
\hline
\end{tabular}

Note: Data are expressed as the mean \pm SD.

Abbreviations: $\mathrm{n}$, number; CAK, cumulative air kerma; DAP, dose area product; $\mathrm{SD}$, standard deviation. 
the LRA may be a safer approach when performing primary PCI among STEMI patients than the RRA, and it can help to decrease the radiation dose absorbed by patients.

Several factors may have played an important role in the reduction of the needle-to-balloon time and fluoroscopy time. Anatomical variations of the right radial and subclavian arteries may lead to needing more time when performing angiography and engaging the infarct-related artery with the guide catheter. The catheters must be rotated to afford the S-shaped geometry of the subclavian-innominate-aorta axis in the RRA. ${ }^{8,23}$ Conversely, the LRA may have an anatomical advantage because the vascular anatomy of the epiaortic vessels offers more direct access to the ascending aorta, thus allowing for quicker and easier delivery of a PCI device, such as a balloon or aspiration catheter. Therefore, the difficulties of catheter manipulation and PCI device delivery may lead to an increase in the blood flow restoration time in the RRA. On the other hand, the operator's experience is related to the procedure's success rate and duration. In this study, since all operators have been well trained to perform the left radial PCI procedure before the study, reperfusion time related to the LRA was not prolonged for less experienced operators.

\section{Study limitations}

There are some potential limitations of this study. First, the present study is a single-center research with a relatively small sample size. Future larger scale investigations will be necessary to confirm our findings. Second, the follow-up period of this study was short. Longer follow-up periods should be carried out to evaluate the safety of the transradial approach. Third, radiation exposure was evaluated only for the patients, whereas the radiation dose to the operators was not measured. A possible concern is that the LRA may increase the operator's radiation exposure. Finally, the operators of this study are highly experienced in transradial primary PCI, and the study subjects are Chinese populations whose body sizes (average body mass index of $25 \mathrm{~kg} / \mathrm{m}^{2}$ ) are smaller than those of Caucasians. Therefore, our findings had limited generalizability and were not applicable to Caucasians.

\section{Conclusion}

Primary PCI can be performed via the LRA with earlier blood flow restoration in the infarct-related artery and lower radiation exposure when compared with the RRA. The clinical implication of this study is that the LRA may become a feasible and attractive alternative when performing primary PCI for STEMI patients.

\section{Acknowledgments}

The results of this study were presented in part at the 3rd Advanced International Masterclass AIM-RADIAL 2014, Chicago (IL, USA) and the 25th Great Wall International Congress of Cardiology and Asia Pacific Heart Congress 2014, Beijing, People's Republic of China. We are indebted to the nurses and technicians of the catheter lab at our institution for their daily collaboration and technical support.

\section{Disclosure}

The authors report no conflicts of interest in this work.

\section{References}

1. Archbold RA, Robinson NM, Schilling RJ. Radial artery access for coronary angiography and percutaneous coronary intervention. $B M J$. 2004;329(7463):443-446.

2. Agostoni P, Biondi-Zoccai GG, de Benedictis ML, et al. Radial versus femoral approach for percutaneous coronary diagnostic and interventional procedures; Systematic overview and meta-analysis of randomized trials. J Am Coll Cardiol. 2004;44(2):349-356.

3. Rao SV, Ou FS, Wang TY, et al. Trends in the prevalence and outcomes of radial and femoral approaches to percutaneous coronary intervention: a report from the National Cardiovascular Data Registry. JACC Cardiovasc Interv. 2008;1(4):379-386.

4. Jolly SS, Amlani S, Hamon M, Yusuf S, Mehta SR. Radial versus femoral access for coronary angiography or intervention and the impact on major bleeding and ischemic events: a systematic review and metaanalysis of randomized trials. Am Heart J. 2009;157(1):132-140.

5. Burzotta F, Trani C, Mazzari MA, et al. Vascular complications and access crossover in 10,676 transradial percutaneous coronary procedures. Am Heart J. 2012;163(2):230-238.

6. Arzamendi D, Ly HQ, Tanguay JF, et al. Effect on bleeding, time to revascularization, and one-year clinical outcomes of the radial approach during primary percutaneous coronary intervention in patients with STsegment elevation myocardial infarction. Am J Cardiol. 2010;106(2): $148-154$.

7. Dominici M, Diletti R, Milici C, et al. Left radial versus right radial approach for coronary artery catheterization: a prospective comparison. J Interv Cardiol. 2012;25(2):203-209.

8. Sciahbasi A, Romagnoli E, Burzotta F, et al. Transradial approach (left vs right) and procedural times during percutaneous coronary procedures: TALENT study. Am Heart J. 2011;161(1):172-179.

9. Pellica F, Trani C, Biondi-Zoccai GG, et al; Prospective Registry of Vascular Access in Interventions in Lazio Region (PREVAIL) Study Group. Comparison of the feasibility and effectiveness of transradial coronary angiography via right versus left radial artery approaches (from the PREVAIL Study). Am J Cardiol. 2012;110(6):771-775.

10. Hu H, Fu Q, Chen W, Wang D, Hua X, Chen B. A prospective randomized comparison of left and right radial approach for percutaneous coronary angiography in Asian populations. Clin Interv Aging. 2014;9: 963-968.

11. Navarese EP, De Luca G, Castriota F, et al. Low-molecular-weight heparins vs. unfractionated heparin in the setting of percutaneous coronary intervention for ST-elevation myocardial infarction: a metaanalysis. J Thromb Haemost. 2011;9(10):1902-1915.

12. Ochiai M, Isshiki $\mathrm{T}$, Toyoizumi $\mathrm{H}$, et al. Efficacy of transradial primary stenting in patients with acute myocardial infarction. Am J Cardiol. 1999; 83(6):966-968, A10.

13. Weaver AN, Henderson RA, Gilchrist IC, Ettinger SM. Arterial access and door-to-balloon times for primary percutaneous coronary intervention in patients presenting with acute ST-elevation myocardial infarction. Catheter Cardiovasc Interv. 2010;75(5):695-699. 
14. Louvard Y, Ludwig J, Lefèvre T, et al. Transradial approach for coronary angioplasty in the setting of acute myocardial infarction: a dualcenter registry. Catheter Cardiovasc Interv. 2002;55(2):206-211.

15. Valsecchi O, Musumeci G, Vassileva A, et al. Safety, feasibility and efficacy of transradial primary angioplasty in patients with acute myocardial infarction. Ital Heart J. 2003;4(5):329-334.

16. Vorobcsuk A, Kónyi A, Aradi D, et al. Transradial versus transfemoral percutaneous coronary intervention in acute myocardial infarction: systematic overview and meta-analysis. Am Heart J. 2009;158(5):814-821.

17. Wu CJ, Fang HY, Cheng CI, et al. The safety and feasibility of bilateral radial approach in chronic total occlusion percutaneous coronary intervention. Int Heart J. 2011;52(3):131-138.

18. Burzotta F, De Vita M, Lefevre T, Tommasino A, Louvard Y, Trani C. Radial approach for percutaneous coronary interventions on chronic total occlusions: technical issues and data review. Catheter Cardiovasc Interv. 2014;83(1):47-57.

19. Norgaz T, Gorgulu S, Dagdelen S. A randomized study comparing the effectiveness of right and left radial approach for coronary angiography. Catheter Cardiovasc Interv. 2012;80(2):260-264.
20. Cannon CP, Gibson CM, Lambrew CT, et al. Relationship of symptomonset-to-balloon time and door-to-balloon time with mortality in patients undergoing angioplasty for acute myocardial infarction. JAMA. 2000;283(22):2941-2947.

21. De Luca G, Suryapranata H, Ottervanger JP, Antman EM. Time delay to treatment and mortality in primary angioplasty for acute myocardial infarction: every minute of delay counts. Circulation. 2004;109(10): 1223-1225.

22. Larsen $\mathrm{P}$, Shah S, Waxman S, et al. Comparison of procedural times, success rates, and safety between left versus right radial arterial access in primary percutaneous coronary intervention for acute ST-segment elevation myocardial infarction. Catheter Cardiovasc Interv. 2011; 78(1):38-44.

23. Sciahbasi A, Romagnoli E, Trani C, et al. Evaluation of the "learning curve" for left and right radial approach during percutaneous coronary procedures. Am J Cardiol. 2011;108(2):185-188.
Clinical Interventions in Aging

\section{Publish your work in this journal}

Clinical Interventions in Aging is an international, peer-reviewed journal focusing on evidence-based reports on the value or lack thereof of treatments intended to prevent or delay the onset of maladaptive correlates of aging in human beings. This journal is indexed on PubMed Central, MedLine,

\section{Dovepress}

CAS, Scopus and the Elsevier Bibliographic databases. The manuscript management system is completely online and includes a very quick and fair peer-review system, which is all easy to use. Visit http://www.dovepress. com/testimonials.php to read real quotes from published authors. 